\author{
RESEARCH ARTICLE \\ 10.1029/2019JB018688 \\ Key Points: \\ - Sri Lanka has mostly isostatically \\ compensated 30-40 km thick crust \\ - $V_{P} / V_{S}$ ratios are between 1.60 and \\ 1.82 and predominantly favor a \\ felsic to intermediate bulk crustal \\ composition \\ - A midcrustal westward dipping \\ interface could be related to \\ the thrust contact between the \\ Highland Complex and the Vijayan \\ Complex
}

Supporting Information:

- Supporting Information S1

Correspondence to:

J. Dreiling,

dreiling@gfz-potsdam.de

Citation:

Dreiling, J., Tilmann, F.,

Yuan, X., Haberland, C., \&

Seneviratne, S. W. M. (2020). Crustal

structure of Sri Lanka derived from

joint inversion of surface wave

dispersion and receiver functions

using a Bayesian approach. Journal

of Geophysical Research: Solid Earth,

125, e2019JB018688. https://doi.org/

10.1029/2019JB018688

Received 11 SEP 2019

Accepted 5 APR 2020

Accepted article online 21 APR 2020

(C)2020. The Authors.

This is an open access article under the terms of the Creative Commons

Attribution License, which permits use, distribution and reproduction in any medium, provided the original work is properly cited.

\section{Crustal Structure of Sri Lanka Derived From Joint Inversion of Surface Wave Dispersion and Receiver Functions Using a Bayesian Approach}

\author{
Jennifer Dreiling ${ }^{1,2}(\mathbb{D})$, Frederik Tilmann ${ }^{1,2}(\mathbb{D})$, Xiaohui Yuan ${ }^{1}(\mathbb{D})$, Christian Haberland ${ }^{1}$, \\ and S. W. Mahinda Seneviratne ${ }^{3}$ \\ ${ }^{1}$ Department of Geophysics, Helmholtz-Zentrum Potsdam, German Research Centre for Geosciences (GFZ), Potsdam, \\ Germany, ${ }^{2}$ Institute for Geological Sciences, Freie Universität Berlin, Berlin, Germany, ${ }^{3}$ Geological Survey and Mines \\ Bureau (GSMB), Pitakotte, Sri Lanka
}

\begin{abstract}
We study the crustal structure of Sri Lanka by analyzing data from a temporary seismic network deployed in 2016-2017 to shed light on the amalgamation process from a geophysical perspective. Rayleigh wave phase dispersion curves from ambient noise cross correlation and receiver functions were jointly inverted using a transdimensional Bayesian approach. The Moho depths in Sri Lanka range between 30 and $40 \mathrm{~km}$, with the thickest crust (38-40 km) beneath the central Highland Complex (HC). The thinnest crust (30-35 km) is found along the west coast, which experienced crustal thinning associated with the formation of the Mannar Basin. $V_{P} / V_{S}$ ratios lie within a range of 1.60-1.82 and predominantly favor a felsic to intermediate bulk crustal composition with a significant silica content of the rocks. A major intracrustal $(18-27 \mathrm{~km})$, slightly westward dipping $\left(\sim 4.3^{\circ}\right)$ interface with high $V_{S}$ $(\sim 4 \mathrm{~km} / \mathrm{s})$ underneath is prominent in the central HC, continuing into the western Vijayan Complex (VC). The discontinuity might have been part of the respective units prior to the collision and could be an indicator for the proposed tilting of the Wanni Complex/HC crustal sections. It might also be related to the deep crustal $\mathrm{HC} / \mathrm{VC}$ thrust contact with the $\mathrm{VC}$ as an indenting promontory of high $V_{S}$. A low-velocity zone in the central $\mathrm{HC}$ could have been caused by fluid influx generated by the thrusting process.
\end{abstract}

\section{Introduction}

Sri Lanka occupied a key region in both the assembly and the multistage breakup of Gondwana. Many petrological, geochemical, and geochronological studies have been conducted to reconstruct the processes acting during the amalgamation. However, little is known about the seismic structure of the island. Until mid-2016, only three permanent seismic stations existed on the island. Pathak et al. (2006), Rai et al. (2009), and Mukherjee et al. (2020) analyzed receiver functions (RFs) from the permanent stations and estimated Moho depths and $V_{P} / V_{S}$ ratios. Prasanna et al. (2013) used gravity inversion, and Mishra et al. (2006) modeled gravity anomalies within Sri Lanka and other continental fragments of Gondwana to determine the crustal thickness and structure beneath the island.

In 2016-2017, the Geological Survey and Mines Bureau of Sri Lanka and the German Research Centre for Geosciences installed and maintained the first broadband seismic network on the island (Figure 1), consisting of 30 stations running for a period of 13 months. Here, we image the crustal structure of Sri Lanka using the new seismic data. We performed a joint inversion of dispersion curves from seismic ambient noise with RFs using a Bayesian approach, which allows us to compute a collection of possible models and to estimate the uncertainty of the model parameters.

\subsection{Geologic Background}

Sri Lanka is mostly composed of Precambrian crust; only the northern and northwestern coasts show younger Jurassic-Quaternary sedimentary deposits (Figure 1). The Precambrian basement consists of three major units, namely, from west to east, the Wanni Complex (WC), the Highland Complex (HC), and the Vijayan Complex (VC). Some HC erosion remnants (Klippen) occur around Buttala, Kataragama, and Kuda Oya in the southern part of the VC. The Kadugannawa Complex (KC) is a relatively small unit located between the WC and the HC. It is contentious whether it is part of the WC, part of the HC or the root zone 


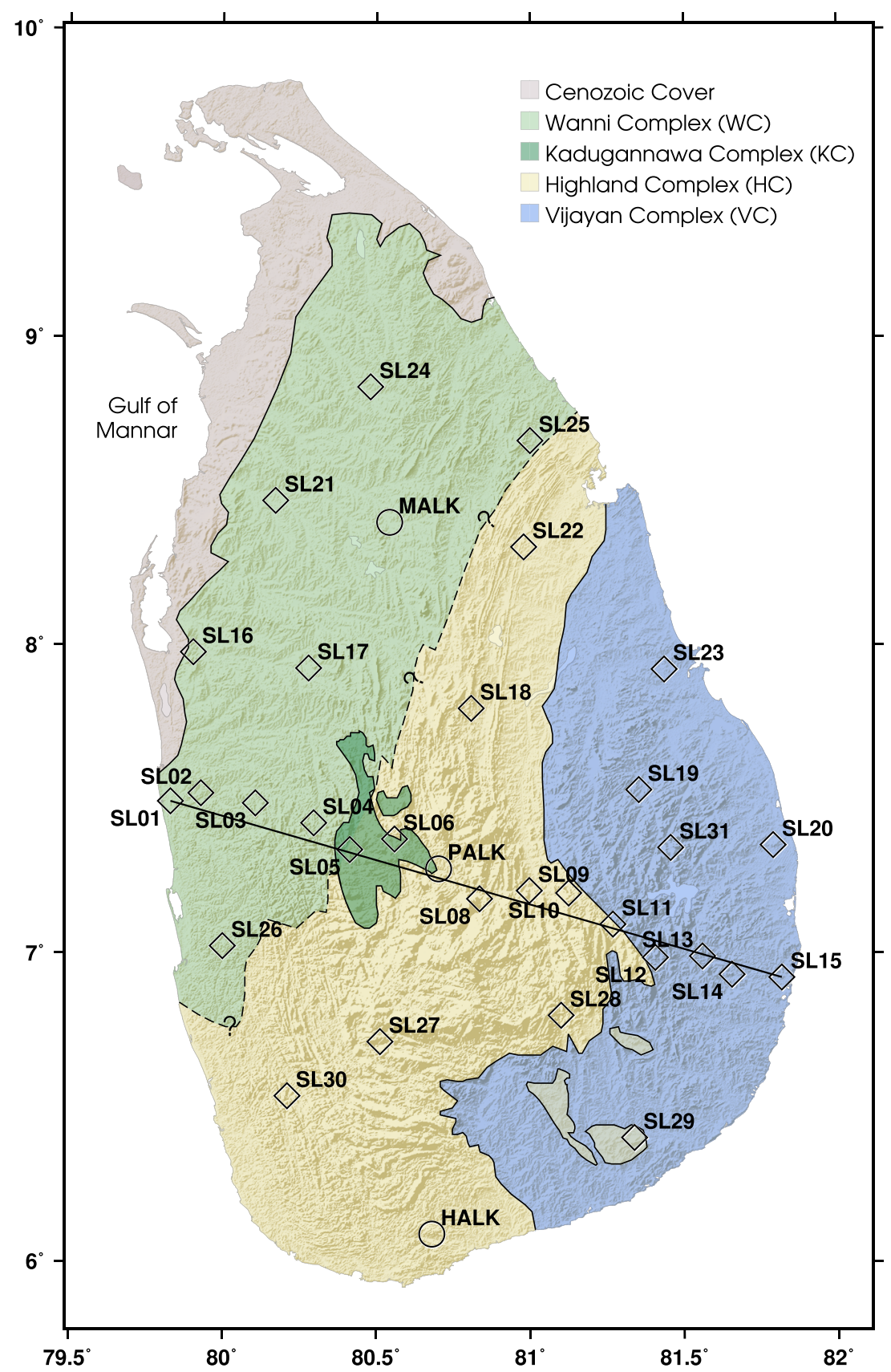

Figure 1. Map of seismic stations and major lithotectonic units (modified after Dissanayake \& Chandrajith, 1999) in Sri Lanka. Diamonds represent station locations of the temporary seismic array (FDSN code: 1A, 2016-2017). Circles denote three permanent stations (MALK, PALK, and HALK). The black line indicates the profile location for a cross section.

of an island arc (and references therein Cooray, 1994). The $\mathrm{WC} / \mathrm{HC}$ represents as a combined unit a tilted section of former middle to lower crust, with the $\mathrm{HC}$ representing the lower level. The $\mathrm{KC}$ is at a crustal level between the WC and the HC (Kehelpannala, 1997; Kriegsman, 1994; Sandiford et al., 1988).

The lithotectonic units of Sri Lanka show amphibolite to granulite facies metamorphic rocks of sedimentary and igneous heritage (Kehelpannala, 2003, and references therein). The WC predominantly shows rocks of upper amphibolite to granulite facies and consists of supracrustal rocks, granitoid gneisses, charnockitic gneisses, and granites, together with a variety of metasediments of predominantly semipelitic to pelitic composition (Dissanayake \& Chandrajith, 1999; Kehelpannala, 2003; Kröner et al., 1994). The granulite 
facies HC is composed half of supracrustal and metasedimentary rocks and half of metaigneous gneisses of granitoid origin (Kröner et al., 1991). The mainly amphibolite facies VC consists of granitoid gneisses and metadiorites, metagabbros, migmatites, mafic dykes, and minor metasedimentary enclaves (Kehelpannala, 2003, and references therein).

The contact between the WC and the HC is controversial due to the absence of a structural break between them (Kröner \& Brown, 2005). Stretching lineations, shear sense indicators, and sheath folds demonstrate that a collision has occurred in a NNW-SSE direction; that is, the WC/KC was moving on top of the HC from NNW toward SSW (Kehelpannala, 2003, and references therein). The boundary between the WC and the $\mathrm{KC}$ is less clear, while that between the $\mathrm{KC}$ and the $\mathrm{HC}$ is well defined. The contact between the HC and the $\mathrm{VC}$ is considered to be a deep crustal, subhorizontal ductile shear and thrust zone (Kehelpannala, 2003; Kleinschrodt, 1994, 1996, and references therein). E-W stretching lineations in the VC and nearly $\mathrm{N}-\mathrm{S}$ stretching lineations and shear sense indicators at and close to the shear zone suggest a nearly E-W directed transpressional collision between the combined WC/HC unit and the VC (Kehelpannala, 1997, and references therein). The general trend of subhorizontal fold envelopes suggests the thrust to underlie large parts of the HC; Klippen south of the HC prove that the thrust plane extended nearly up to the south coast (Kleinschrodt, 1994, 1996). Furthermore, Kleinschrodt (1994) suggests that the HC was thrust over the VC with a ramp-flat geometry or a low-angle thrust that steepens to higher crustal levels.

The amalgamation of the Sri Lankan complexes (visualized by, e.g., Kehelpannala, 2004) took place within the framework of the Pan-African continental collision between West and East Gondwana. A well-established theory suggests a stepwise assembly of the Precambrian arcs, with initial collision of the WC and HC fragments. As a unified block the WC/HC has experienced six phases of ductile deformation (D1-D6, during 0.61 to $0.55 \mathrm{Ga}$ ), which are not seen for the VC (Kehelpannala, 1997). The evidence therefore suggests an early stage collision of the WC/HC unit with the VC at D5 (0.58 Ga), and the WC/HC subsequently being thrust over the VC (Kehelpannala, 2003, and references therein). Based on posttectonic intrusion by Cambrian granites and syenites through all three units, that is, WC, HC, and VC, the fragments of Sri Lanka were united at $0.55 \mathrm{Ga}$. Most of the older structures have been obliterated by the strong Pan-African noncoaxial strain (Kehelpannala, 1997). The Mannar Basin (west of Sri Lanka, partly onshore, Figure 1) has been formed during Gondwana breakup, which initiated at approximately 165 Ma (Royer \& Coffin, 1992). A great amount of rifting between India and Sri Lanka together with strike slip movement and anticlockwise rotation of Sri Lanka was responsible for significant widening and rapid subsidence in the basin (Kularathna et al., 2015) and is associated with strong crustal thinning along the west coast.

\subsection{Seismic Data}

Until May 2016, the island of Sri Lanka was equipped with only three seismic stations: PALK, MALK, and HALK. PALK is an IRIS/IDA station and has been operating since 2000 (SIOO, 1996). MALK and HALK are GEOFON stations and have been operating since 2010 (GEOFON Data Centre, 1993). In mid-2016, the Geological Survey and Mines Bureau and the German Research Centre for Geosciences deployed a network of 30 three-component broadband stations (Seneviratne et al., 2016; Figure 1), which recorded continuous data for a period of 13 months.

The temporary array was designed to perform seismic ambient noise and RF analyses as well as local earthquake studies. Fourteen temporary stations and the permanent station PALK form a $230 \mathrm{~km}$ long profile across the island, from the west to the east coast, perpendicular to the predominant geologic strike (profile in Figure 1). Interstation distances are about $15 \mathrm{~km}$. Sixteen more stations are distributed on the island with a larger spacing of about $50 \mathrm{~km}$.

Three stations (SL04, SL14, and SL30) were operating only for a short period of time. SL14 failed after just 13 days, which was too short to record enough earthquake signals or to recover stable Green's functions; hence, we excluded it from both analyses. Stations SL04 and SL30 were recording for 85 and 30 days, respectively. These stations were included for the seismic ambient noise analysis but discarded for RF computation, as too few events occurred during operational time. The stations included in this study and the time period considered for further analyses are summarized in Table 1.

\section{Seismic Ambient Noise Correlation and Tomography}

In order to prepare the data for calculating the cross-correlation stacks, the linear trend and the mean were subtracted from the raw data and a low-pass filter was applied prior to decimation to prevent aliasing effects. 
Table 1

Seismic Broadband Stations and Time Span Included in This Study

\begin{tabular}{lccccc}
\hline Network & FDSN & Stations & SR (Hz) & SWD Time Span & RF Time Span \\
\hline Temporary & 1A & SL01-SL31 & 100 & $06 / 2016$ to 06/2017 & $06 / 2016$ to 06/2017 \\
GEOFON & GE & MALK, HALK & 50 & $05 / 2016$ to $08 / 2017$ & $01 / 2015$ to $12 / 2017$ \\
IRIS/IDA & II & PALK & 40 & $05 / 2016$ to 08/2017 & $01 / 2015$ to $12 / 2017$ \\
\hline
\end{tabular}

Note. SR: sampling rate; SWD: surface wave dispersion; RF: receiver functions. The temporary Network 1A is our primary data source.

The threshold was set to $85 \%$ of the new Nyquist frequency $(2.125 \mathrm{~Hz})$. The data were downsampled to a sampling rate of $5 \mathrm{~Hz}$, with subsequent instrument response removal.

For ambient noise cross correlation, we applied the preprocessing procedures suggested by Bensen et al. (2007). The instrument corrected data were clipped at 3 standard deviations and band-pass filtered between 0.01 and $1.25 \mathrm{~Hz}$. Subsequently, spectral whitening and 1 bit normalization were applied. The cross correlation was performed by correlating $1 \mathrm{hr}$ segments of all station and component combinations and subsequently rotating the full Green's tensor stream from the ZNE to the ZRT coordinate system. The correlograms resulting from one day were stacked. Green's functions were then generated by stacking the daily stacks for the time period available. This resulted in a final correlogram stack for each of the 496 station pairs and for each of the components. Here, we consider combinations of the radial and vertical component for the Rayleigh surface wave, that is, vertical-vertical (ZZ), radial-radial (RR), radial-vertical (RZ), and vertical-radial (ZR). Figure S1 in the supporting information shows record sections of cross correlograms for the $\mathrm{ZZ}$ component.

Surface wave dispersion (SWD) was determined from the phase of the fundamental mode Rayleigh wave, based on the zero crossings of the real part of the correlation spectrum (Aki, 1957; Ekström et al., 2009). The $2 \pi$ ambiguity leads to a family of possible period-phase velocity relations. Therefore, the average phase velocity dispersion for Sri Lanka was computed and used as a guide for selection of the most likely branch for each station pair. To retrieve phase velocity measurements, we used the tool GSpecDisp (Sadeghisorkhani et al., 2017). Dispersion curves were determined for the ZZ, RR, RZ, and ZR components separately, resulting in 478, 422, 440, and 454 successful measurements, respectively. For 385 station pairs, all four components could be picked. To retrieve the final Rayleigh wave dispersion curve for each station pair, the four dispersion curves were averaged after interpolation (Figure 2, left).

The final 385 phase velocity dispersion curves for Sri Lanka are illustrated in Figure 2, right. The velocities increase from $2.9-3.3 \mathrm{~km} / \mathrm{s}$ at the period of $1 \mathrm{~s}$ to $3.7-4.0 \mathrm{~km} / \mathrm{s}$ at $30 \mathrm{~s}$. The variations of phase velocities cover a narrow band with an average width of $0.35 \mathrm{~km} / \mathrm{s}$. More than 300 phase velocity measurements were made at most of the periods. At periods $>13 \mathrm{~s}$ the number of measurements continuously decreases. As measurements were only considered if the interstation distance is at least 1.2 wave lengths (e.g., Ekström et al., 2009),
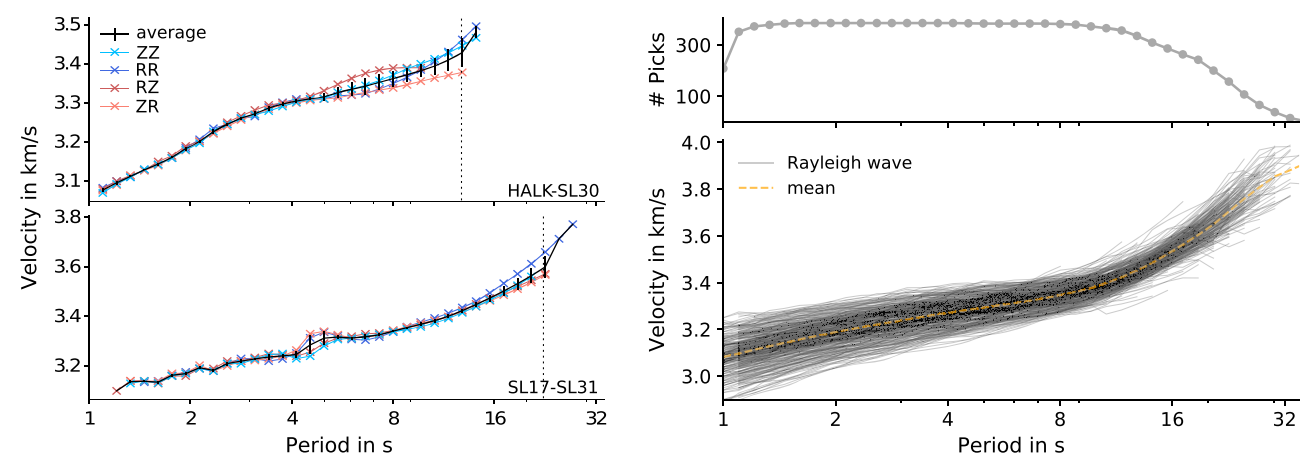

Figure 2. (left) Construction of average dispersion curve from four measured Rayleigh wave components (ZZ, RR, RZ, and ZR) for two station pairs. The black line shows the average curve including standard deviations. The dashed vertical line marks the maximum period considered. (right, bottom) Final Rayleigh wave dispersion curves for all the individual station pairs. (right, top) Number of measured phase velocities at discrete periods. 
the longer periods demand sufficiently large interstation distances, which are limited by the array design. The signal-to-noise ratio also decreases at longer distances.

For travel time tomography, we used the Fast Marching Surface wave Tomography package (Rawlinson, 2005; Rawlinson \& Sambridge, 2005). We gridded our study area into $12 \times 15$ cells, each having a dimension of $\sim 25 \times 33 \mathrm{~km}$. We performed five iterations, as the residuals rapidly decreased and stabilized. We assumed $2.5 \%$ outliers, which were removed at the second iteration. As starting model each grid node was set to the period dependent mean velocity (see the supporting information for trade-off curves, Figure S2, and outlier preselection.)

A selection of tomography results, including ray path coverage, is illustrated in Figure S3. At shorter periods (3 s), velocity contours roughly follow the geological boundaries along a NNE-SSW direction. The highest velocities are around the $\mathrm{WC} / \mathrm{KC} / \mathrm{HC}$ contact and decrease with distance toward the west and east. The lowest velocities are found in the $\mathrm{SE}$ of the island. At intermediate periods $(12 \mathrm{~s})$, high velocities dominate central Sri Lanka, surrounding the KC. The longer periods $(21 \mathrm{~s})$ show slightly higher velocities in the north than in the south.

Final dispersion curves were constructed from the tomography results. Phase velocities were collected at each discrete period from the interpolated grid data (Figure S3) at the location of each seismic station. The resulting dispersion curves were smoothed by averaging over three adjacent period values.

\section{RFs and $\mathrm{H} \kappa$ Stack Analysis}

We considered all earthquakes with magnitudes $M>5.5$ and epicentral distances of $30-90^{\circ}$ (based on the U.S. Geological Survey catalog). The temporary network recorded 246 of such earthquakes; the permanent stations registered 636 events. Most of the events are located NE-SE of Sri Lanka within a back azimuthal range of $40-120^{\circ}$, specifically along the West Pacific and Indonesian plate boundaries. The data cover a slowness range of $4.6-8.8 \mathrm{~s} /{ }^{\circ}$.

To ensure good quality RFs, we selected seismograms with signal-to-noise ratios $>2.5$ on the vertical component. The selection process resulted in 1979 traces from 267 events (see Table S1). For RF computation, each trace was filtered (band pass: $0.05-5 \mathrm{~Hz}$ ), decimated to a sampling rate of $20 \mathrm{~Hz}$, and trimmed to $5 \mathrm{~s}$ before and $30 \mathrm{~s}$ after the $P$ onset. Subsequently, each trace was rotated from the ZNE into the local LQT ray coordinate system (Kind et al., 2012) to separate the wave types $(P, S V, S H)$ onto own components. The rotation is based on the theoretical incidence angle of the $P$ wave at the surface, assuming a surface $V_{S}$ of $3.5 \mathrm{~km} / \mathrm{s}$. $P$-to- $S$ converted waves are polarized on the $Q$ component $(S V)$, hence it was deconvolved with the respective $L$ component to remove source-time effects, utilizing water level stabilization (level: 0.001) and low-pass filtering with a Gaussian function (Gauss factor: 1.0). The resulting RFs were sorted according to slowness and stacked in bins of $0.2 \mathrm{~s} /{ }^{\circ}$ without amplitude normalization. The bin-stacked RFs show a coherent signal, as can be seen in Figure S4. The RFs were not moveout corrected for the final stack, as the moveout correction has a strong effect on the multiple timing, which would result in biased interface depths in the inversion.

RFs along the main profile are illustrated in Figure 3. The independently derived station stacks show consistent phases throughout the profile, especially regarding the Ps phase and its multiples. An intracrustal direct phase (and the first multiple) is visible at the central stations SL06-SL10 and fades at SL11-SL13. This intracrustal arrival indicates a discontinuity at midcrustal depth with a strong velocity contrast.

The $\mathrm{H} \kappa$ stack grid search method following Zhu and Kanamori (2000) was applied to estimate Moho depths and $V_{P} / V_{S}$ ratios. The method is illustrated in Figure $S 5$ for a selection of stations. Moho depths for Sri Lanka range between 29.5 and $40 \mathrm{~km}$ with a typical uncertainty of $\sim 0.7 \mathrm{~km} ; V_{P} / V_{S}$ ranges between 1.60 and 1.82 with an average of 1.72 and a typical uncertainty of 0.02 (see Table S2). The Moho estimates strongly depend on the crustal $V_{P}$, which we assumed to be $6.5 \mathrm{~km} / \mathrm{s}$ for each station; this is reasonable for felsic amphibolite and granulite facies continental crust (Huang et al., 2013). A misestimation of $0.1 \mathrm{~km} / \mathrm{s}$ would result in a crustal thickness variation of about $1 \mathrm{~km}$. The $V_{P} / V_{S}$ ratios do not depend significantly on the assumed $V_{P}$.

\section{Bayesian Inversion of SWD and RF}

As a final step, RFs and phase velocity dispersion curves were jointly inverted with a Markov chain Monte Carlo (McMC) transdimensional Bayesian inversion tool (BayHunter; Dreiling \& Tilmann, 2019), where we 


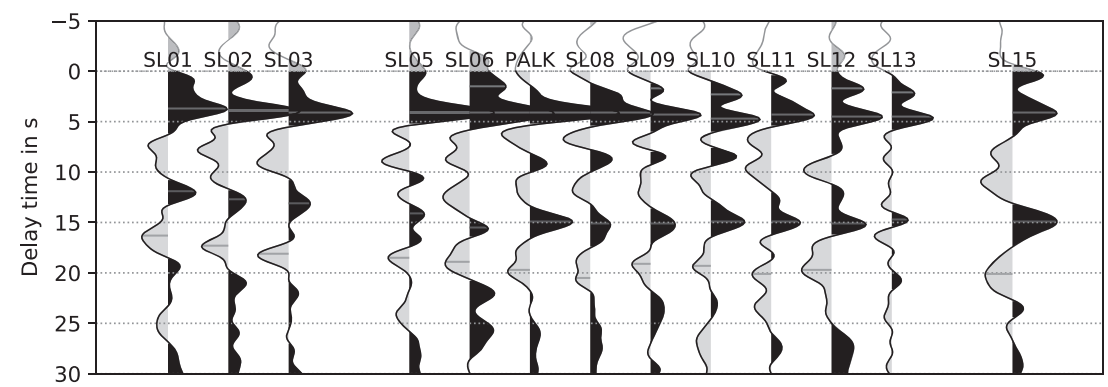

Figure 3. Receiver function stacks along the main profile from SL01 to SL15. Brown markers indicate clear Ps converted phase at the Moho and corresponding multiples. Indications for a midcrustal converter are marked in blue.

solve for the velocity-depth structure, the number of layers, the noise parameters, and the crustal average $V_{P} / V_{S}$. While other inversion methods often favor one best model based on the least misfit, an inversion after Bayes's theorem is based on the model's likelihood and results in probability distributions for the parameters of the model. The inversion result is represented by a collection of models, the posterior distributions of which form ideally Gaussian distributions.

The likelihood (equation (1)) is the probability of observing the measured data given a particular model $m$. It is an important measure for accepting and declining proposal models.

$$
\begin{gathered}
p\left(d_{o b s} \mid m\right)=\frac{1}{\sqrt{(2 \pi)^{n}\left|C_{e}\right|}} \exp \left(\frac{-\Phi(m)}{2}\right) \\
\Phi(m)=\left(g(m)-d_{o b s}\right)^{T} C_{e}^{-1}\left(g(m)-d_{o b s}\right)
\end{gathered}
$$

$\Phi(m)$ is the Mahalanobis distance (Mahalanobis, 1936; equation (2)), that is, the multidimensional distance between observed data $d_{o b s}$ and predicted data $g(m)$, both vectors of size $n$, scaled by the data covariance matrix $C_{e}$, which encodes the amplitude and interdata point correlation of the noise. The adjustment of the noise amplitudes essentially controls the weighting between the data sets. For further details about the algorithm and the definition of parameters, refer to Bodin et al. (2012) and to the documentation of BayHunter (Dreiling \& Tilmann, 2019).

For the inversion, the model priors were set to a wide range, that is, a depth range for the interfaces from the surface to $75 \mathrm{~km}, V_{S}$ from 2 to $5 \mathrm{~km} / \mathrm{s}$, and $V_{P} / V_{S}$ from 1.45 to 2.05 . Additionally, a maximum of 20 layers was imposed. The noise amplitude $\sigma_{R F}$ spans from $\sim 0$ to 0.05 , and $\sigma_{S W D}$ from $\sim 0$ to $0.05 \mathrm{~km} / \mathrm{s}$. The correlation parameter $r$ for the correlated noise for RFs was fixed to a value of $r_{R F}=0.96$. For SWD, the noise was assumed uncorrelated. The model priors turn out to be sufficiently wide, relative to the values with significant probability; that is, none of the parameters inverted for have settled on a boundary.

The inversion was performed with 100 chains to ensure multiple independent parameter search paths. Each chain performed 1.8 million iterations, with a 2:1 ratio for the burn-in and exploration phase. The probability distributions for the proposal generation were adjusted during the inversion to maintain an acceptance rate of $\sim 40 \%$. Some chains failed to converge, returning significantly smaller likelihoods than most chains after the burn-in phase. Such chains were declared as outlier chains. For the complete data set, $\sim 5 \%$ of the chains were declared as outlier chains, which indicates that the chosen number of iterations was usually sufficient enough for the chains to converge properly. The final posterior distribution gathers 100,000 models from the exploration phase by subsampling all nonoutlier chains.

The posterior distribution of 100,000 models was sorted according to likelihood and three groups were defined, including the best $25 \%, 50 \%$, and all models, respectively. Figure 4 shows an example of the McMC analysis for SL21, showing $V_{S}$ depth structures and corresponding data fits from randomly selected models from each group, and the posterior distributions of likelihood, joint misfit, SWD and RF noise amplitudes, number of layers, and $V_{P} / V_{S}$ for all models within a group. The grouping (colors) shows the compromises the algorithm made, for example, increasing the number of layers to reduce the noise level and the misfit. Each of the posterior parameters is unimodal. The SWD shows a good data fit. The majority of modeled RFs agrees very well in their signature; however, not all details of the observed waveform can be matched. 

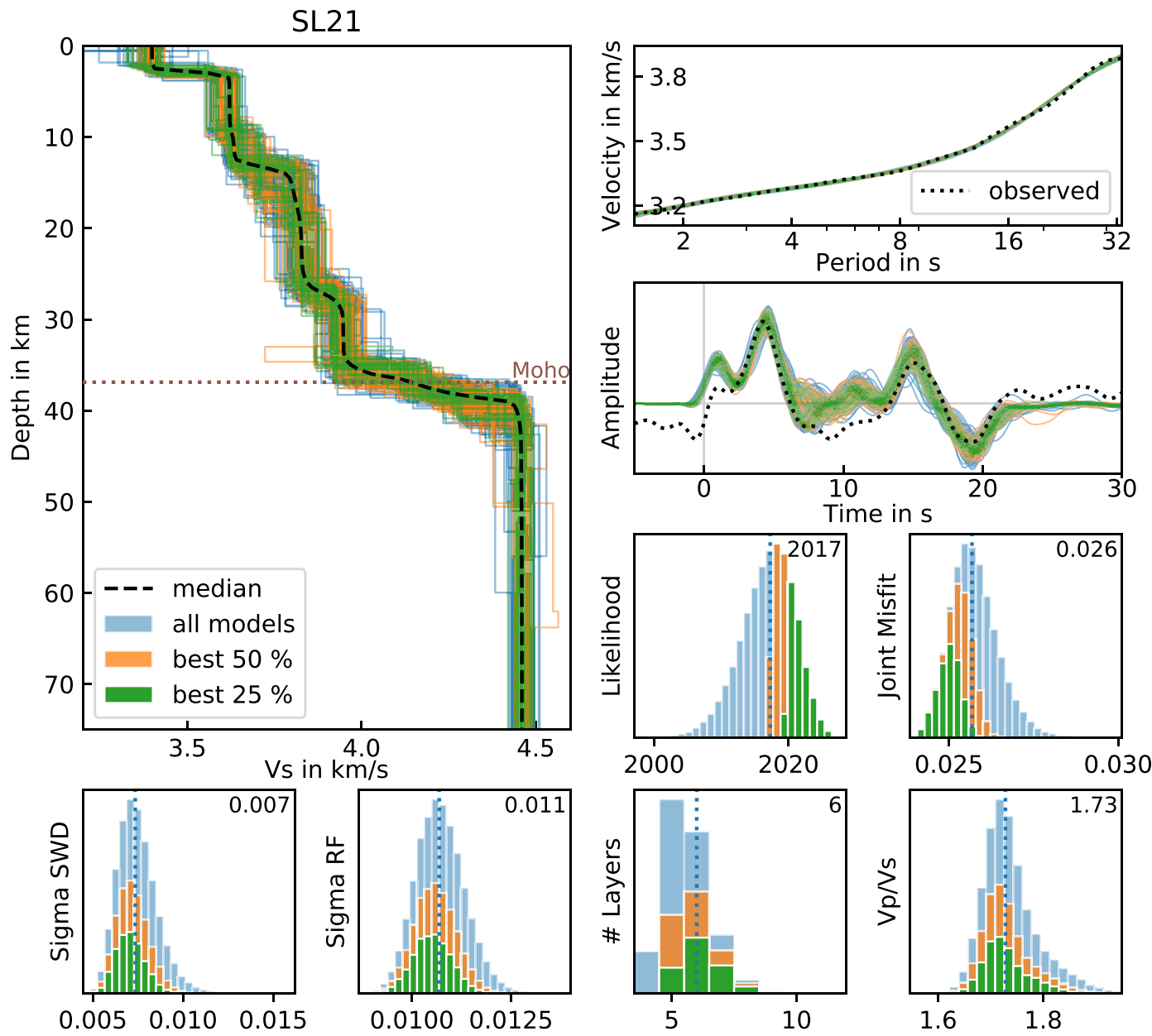

Figure 4. Selection of $V_{S}$ models and corresponding data fits for station SL21, along with posterior distributions of likelihood, joint misfit, SWD and RF noise amplitudes, number of layers and $V_{P} / V_{S}$ ratio. The joint misfit was computed by the sum of the RMS data misfits of SWD and RF. The results are color coded according to the likelihood, that is, three groups showing the best $25 \%, 50 \%$, and all models. Dotted vertical lines illustrate the median (explicit value displayed in the upper right corner of each panel).

The first-order features are modeled in nearly every chain and the $V_{S}$ depth models show similar structures. The median model shows a sharp interface at $3 \mathrm{~km}$ depth and more gradual transitions at 13-15, 26-29, and 35-39 km; the gradual transitions imply a higher uncertainty about the correct interface depth. The Moho discontinuity lies between 35 and $39 \mathrm{~km}$.

The quality of data fit for SL21 is representative for the other stations. (Data fits and average velocity structures are shown for all stations in the supporting information, Figures S6 and S7, respectively. Furthermore, Figures S8a-S8d show results for separate inversions of SWD and RF, and forward modeling examples, to estimate the contribution of each data set to the results.) The posterior distributions are unimodal with the exception of the $V_{P} / V_{S}$ of seven stations (e.g., SL01 and SL16), which show bimodal distributions, and the $V_{P} / V_{S}$ of one station (SL31), which did not yield plausible values (i.e., they settle on a boundary, even if extending the boundary to unrealistic values). Our data are mostly sensitive to $V_{S}$ and contain only weak constraints on $V_{P}$. Thus, $V_{P} / V_{S}$ is a fine-tuning parameter for the $V_{S}$ depth model. For the seven stations showing bimodal $V_{P} / V_{S}$, the algorithm finds two $V_{P} / V_{S}$ optima, causing broader uncertainties of the other parameters due to minor trade-offs. Nevertheless, the resulting distributions for $V_{S}$ are still approximately Gaussian. Also, the most probable $V_{S}$ depth models corresponding to either of the $V_{P} / V_{S}$ optima show nearly identical structures. For the station not converging in $V_{P} / V_{S}$, we compared the results with those from an inversion assuming a fixed $V_{P} / V_{S}(=1.73)$, resulting in models that are very similar in their $V_{S}$ depth structure. 

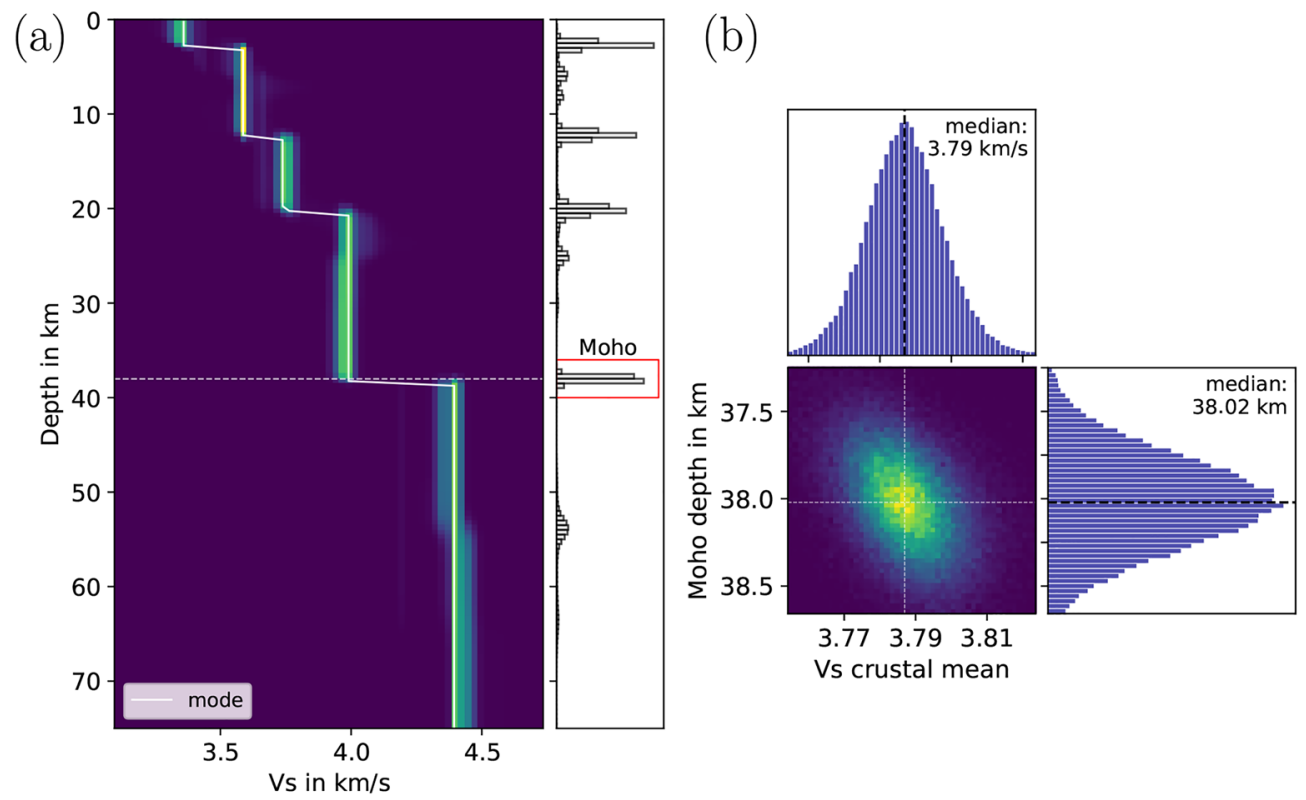

$\begin{array}{lll}3.77 & 3.79 & 3.81\end{array}$ Vs crustal mean

Figure 5. (a) $V_{S}$ posterior distributions and interface depth probabilities for station SL10. The red box marks the interface probability of the Moho. (b) Posterior distributions of the Moho depth and crustal average $V_{S}$. The median Moho depth is $38 \pm 0.2 \mathrm{~km}$, and the average crustal $V_{S}$ is $3.79 \pm 0.01 \mathrm{~km} / \mathrm{s}$.

Figure 5a shows the posterior distributions of $V_{S}$ and interface depth probabilities for station SL10. The surface velocity is $\sim 3.4 \mathrm{~km} / \mathrm{s}$, the interfaces are well defined at $3,12,20$, and $38 \mathrm{~km}$. The Moho depth is between 37 and $39 \mathrm{~km}$, emphasized by the red box in Figure 5a. To retrieve a robust estimate for the Moho depth, the $V_{S}$ models of each station were inspected to give a preselected depth range (e.g., 37-39 km for SL10, 35-39 km for SL21). Each of the 100,000 models was then analyzed to find the interfaces within the preselected range, with the last crustal layer having a $V_{S}<4.2 \mathrm{~km} / \mathrm{s}$. (See Figure $5 \mathrm{~b}$ for the distribution of Moho depths at SL10.) Additional parameters, for example, $V_{S}$ in the last crustal layer, average crustal $V_{S}, V_{S}$ increase across the Moho, and upper mantle $V_{S}$, were extracted. There is a moderate trade-off between those velocities and the crustal thickness, as is illustrated in Figure 5b; although subtle, a deeper Moho estimate is accompanied by a larger average crustal $V_{S}$. This trade-off is well known for RFs but reduced in its impact by the inclusion of SWD. The Moho interface for SL10 is at a depth of $38 \pm 0.2 \mathrm{~km}$ and the average crustal $V_{S}$ is $3.79 \pm 0.01 \mathrm{~km} / \mathrm{s}$. Maps of median Moho depths and average crustal $V_{S}$ are shown in Figure 6 with values as summarized in Table S2.

\section{Crustal Velocity Structure}

Figure 6 shows Moho depths and $V_{P} / V_{S}$ derived by joint Bayesian inversions (a, b) and $\mathrm{H} \kappa$ stack analysis (d, e). A $V_{S}$ cross section along the main profile is illustrated in Figure 7 (see Figure 1 for profile location; see also Figure S9 for $V_{S}$ cross section including Moho depths from the two methods and interface probabilities).

The Moho depths derived from joint inversion and $\mathrm{H} \kappa$ stacking generally agree well with each other. Absolute differences between both methods are between 0.1 and $3.2 \mathrm{~km}$ with a median difference of $0.7 \mathrm{~km}$. The largest Moho depths (38-40 km) are found below the topographic high in the HC. The three northernmost stations in Sri Lanka (SL24, SL25, and MALK) also have a deep Moho interface at $>\sim 38 \mathrm{~km}$ depth. The west coastal stations SL01-SL03 show the thinnest crust (30-35 km). SL20 at the east coast shows a shallow Moho depth in the $\mathrm{H} \kappa$ stack $(\sim 33 \pm 1 \mathrm{~km})$, but not in the joint inversion $(\sim 36 \mathrm{~km})$. We note that there is a strong interface at $\sim 31 \mathrm{~km}$ depth that might have been interpreted as the Moho in the $\mathrm{H} \kappa$ stacking (Figure $8 \mathrm{~b}$, right); this station has the largest Moho deviation of $3.2 \mathrm{~km}$. The Moho interface generally mirrors the topography, that is, higher crustal elevations correspond to larger Moho depths. However, there are few exceptions, which will be discussed in section 6.3 . 

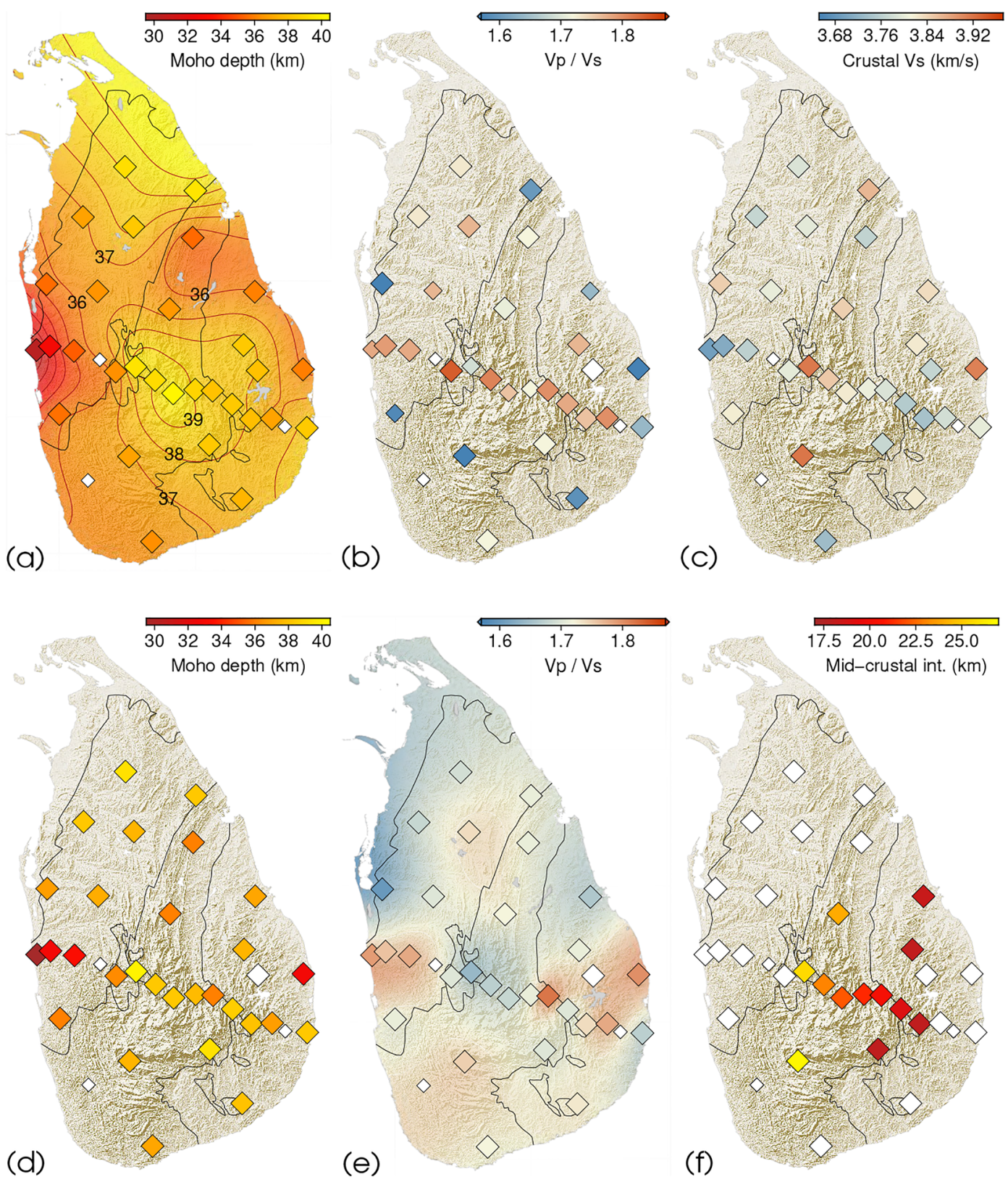

Figure 6. Spatial distribution of (a) Moho depths (contour interval of $1 \mathrm{~km}$ ), (b) $V_{P} / V_{S}$, (c) crustal average $V_{S}$, and (f) midcrustal interface depths derived from the McMC Bayesian inversion. (d and e) The Moho depths and $V_{P} / V_{S}$ ratios derived from $\mathrm{H} \kappa$ stacking. Small white diamonds denote stations with insufficient data for inversion; large white diamonds indicate poorly constrained values (b, d, and e) or that the respective feature is not present (f). The smaller colored symbols in (b) indicate that the distributions are bimodal. Interpolated maps (a and e) show the results considered for interpretation (see explanation in text).

The median $V_{P} / V_{S}$ ratios from joint inversion are between 1.50 and 1.93 , with the majority between 1.68 and 1.80. The $\mathrm{H} \kappa$ stacking results range between 1.60 and 1.82, with the majority of values between 1.66 and 1.73 (Figure 9, left). The differences of $V_{P} / V_{S}$ from both techniques are up to 0.28 with a median difference of $0.03 . V_{P} / V_{S}$ results from both methods agree in their general range for the study region but do not show a common pattern. $\mathrm{H} \kappa$ stacking results for $V_{P} / V_{S}$ are more reliable, as they include a range of RFs and consider the arrival times of $P S$ conversion and multiples directly associated with the slowness. For joint inversion, we considered the RF stack with its median slowness. 


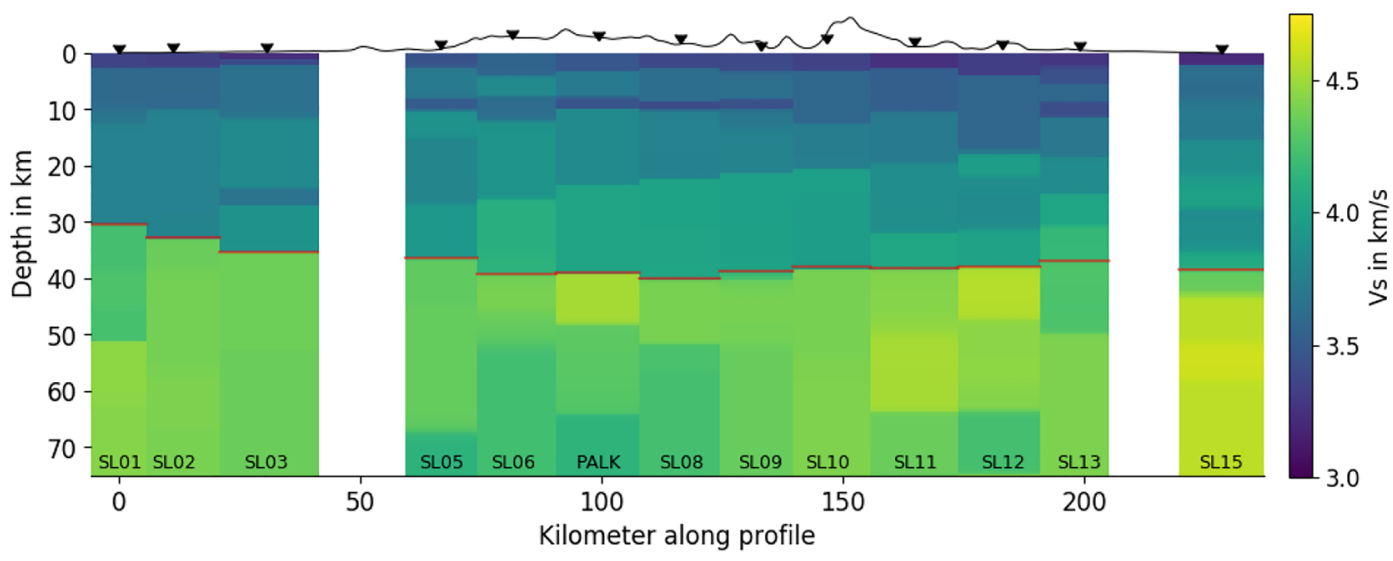

Figure 7. $V_{S}$ cross section along the main profile. The red lines indicate the Moho interface. Topography is exaggerated by a factor of 5 .

The average crustal $V_{S}$ (Figure 6c) ranges from 3.7-3.9 km/s, with increased velocities in the central HC $(>3.83 \mathrm{~km} / \mathrm{s})$, decreasing with distance toward the coastal regions. The southern and westernmost coastal stations (SL01, SL02, and HALK) have the lowest crustal $V_{S}$.

The cross section in Figure 7 (and Figure 8a) shows a prominent westward dipping midcrustal interface with an apparent angle of $\sim 4.3^{\circ}$ between SL06 and SL12, and an average velocity increase from 3.75 to $4 \mathrm{~km} / \mathrm{s}$. These lower crustal high velocities are absent at the stations in the west (SL01-SL05), while the stations in the east (SL11-SL13) show a thinner or interlayered section of the higher velocities. The probability of interfaces (Figure S9) furthermore suggests the dipping interface to be traceable across the entire profile

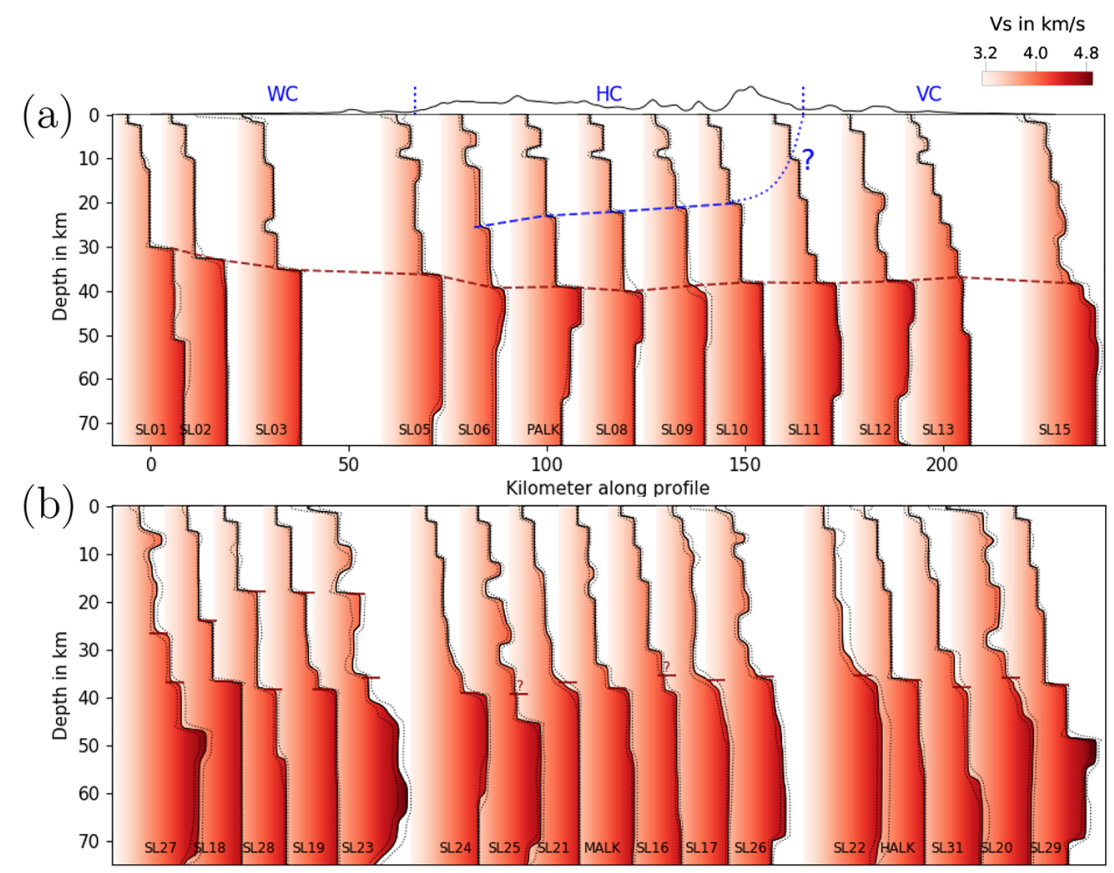

Figure 8. $V_{S}$ models at stations along the main profile (a) and at other stations away from the profile (b). The shallow and deeper red dashed lines indicate the midcrustal and Moho interface, respectively. The blue dotted lines at the surface in (a) mark the approximate surface contacts between the WC, HC, and VC units. The midcrustal interface (blue dashed line) is marked as the $\mathrm{HC} / \mathrm{VC}$ thrust contact, with the dotted line as its possible continuation to the surface. The interpretation is based on Kleinschrodt (1994) and Kriegsman (1995). See details in section 6.4. The $V_{S}$ models in (b) are divided into three groups, which show from left to right (1) stations that include the midcrustal interface, (2) stations in the WC, and (3) stations located in the HC and VC. Moho depths labeled with a question mark indicate an interpretation leaned on surrounding stations (see also SL13). 

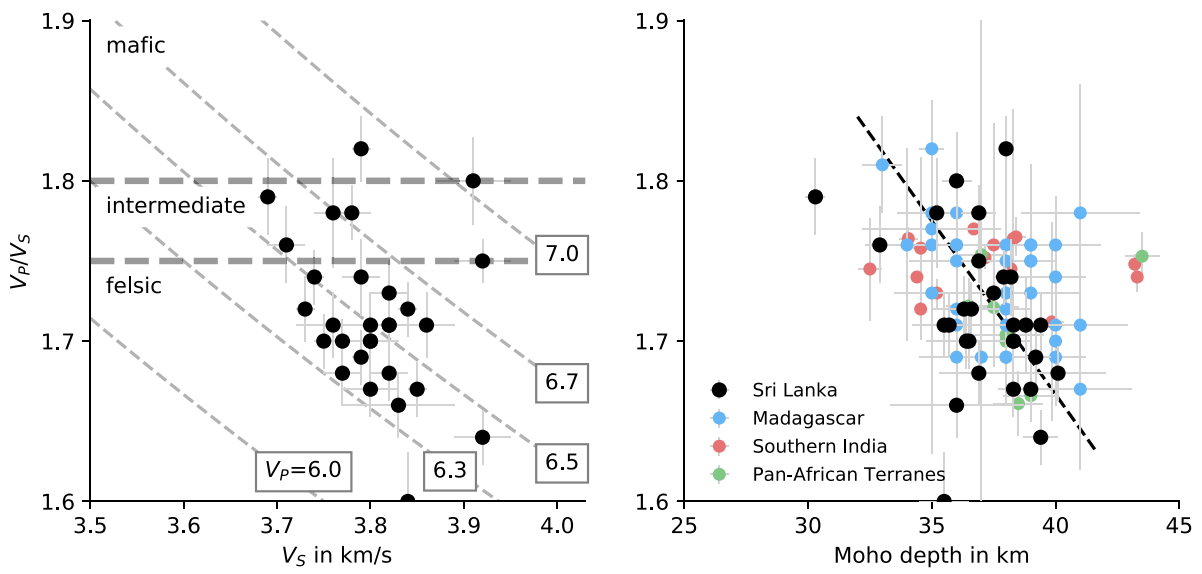

Figure 9. (left) Average crustal $V_{S}$ (joint inversion) and $V_{P} / V_{S}$ ratios (H $\kappa$ stacking) for Sri Lanka observed in this study. Horizontal lines indicate the bounds between felsic, intermediate, and mafic rock compositions according to Christensen (1996). The dashed gray lines indicate contours of constant $V_{P}$. (right) Average crustal $V_{P} / V_{S}(\mathrm{H} \kappa$ stacking) and crustal thicknesses (joint inversion) from our study compared to other Pan-African terranes. Estimates are from the Precambrian domains in southern Madagascar (blue; Rindraharisaona et al., 2017), Kerala Khondalite Belt in southern India (red; Das et al., 2015; Rai et al., 2013), and from single stations in Africa, Madagascar, southern India, Sri Lanka, and East Antarctica (green; Rai et al., 2009); all estimates were derived from $H \kappa$ stacking. Dashed line indicates a weak negative correlation between $V_{P} / V_{S}$ and Moho depths derived in Sri Lanka.

(SL03-SL15). The dotted line in Figure 8a shows an interpretation, which relates the intracrustal interface directly to the $\mathrm{HC} / \mathrm{VC}$ thrust contact (see section 6.4). The interface is also evident on five other stations (Figure 8b, left). Figure 6f shows the spatial extent of the midcrustal discontinuity; values are summarized in Table S2. The midcrustal interface is observable on the central stations in the HC, and on three additional stations in the VC. For the stations in the HC the interface depth lies between $\sim 18-27 \mathrm{~km}$; the interface in the $\mathrm{VC}$ is at $\sim 18 \mathrm{~km}$ depth. The strike has an orientation similar to the geologic strike with a dip toward WNW.

A well-constrained low-velocity zone is observed along SL05-SL09, and SL13 at a depth of $10 \mathrm{~km}$, with $V_{S}$ between 3.4 and $3.6 \mathrm{~km} / \mathrm{s}$. Stations SL15, SL20, SL23, SL25, and SL26 show low-velocity zones at middle to lower crustal depths $(20-30 \mathrm{~km})$; they are located at the western and eastern coastlines.

\section{Interpretation and Discussion}

\subsection{Comparison With Other Geophysical Studies}

The $\mathrm{H} \kappa$ stacking analysis from Pathak et al. (2006) reveals a Moho depth of $34 \pm 1 \mathrm{~km}$ beneath PALK, much shallower compared to our results from two independent analyses, which are $38.2 \pm 0.7$ and $39 \pm 0.3 \mathrm{~km}$ from $\mathrm{H} \kappa$ stacking and Bayesian inversion, respectively. This discrepancy can (partially) be explained by the average $V_{P}$ they assumed for the crust $\left(6.0\right.$ or $6.1 \mathrm{~km} / \mathrm{s}$ ), which is lower than our $V_{P}$ assumption of $6.5 \mathrm{~km} / \mathrm{s}$. Mukherjee et al. (2020) reported Moho depths of $\sim 38 \mathrm{~km}$ and $V_{P} / V_{S}$ between 1.70 and 1.79 for stations PALK, MALK, and HALK, which only partly overlap with our results (Table S2). Rai et al. (2009) obtained a crustal thickness of $37.5 \pm 1 \mathrm{~km}$ and a $V_{P} / V_{S}$ value of $1.72 \pm 0.02$ for PALK. Their estimates of Moho depth and $V_{P} / V_{S}$ agree marginally within error with ours. By forward and inverse modeling of RF and surface wave data they inferred a velocity-depth structure with a low-velocity layer in the upper crust and a midcrustal discontinuity at a depth of $22.5 \mathrm{~km}$. We also observe a shallow low-velocity zone $(\sim 10 \mathrm{~km})$ and an intracrustal discontinuity at $23 \pm 0.4 \mathrm{~km}$.

Mishra et al. (2006) used gravity data and modeled the anomalies along an E-W profile through PALK. They modeled crustal thicknesses of up to $41 \mathrm{~km}$ under the eastern part of the $\mathrm{HC}$, close to our observations, and explain the central gravity high with a higher density crustal section protruding in the upper crust (10-15 km). We also observe a central anomalous higher velocity section, which can correlate to higher densities; however, it is situated in the lowermost crust. A revised gravity modeling including our results might be of interest but would exceed the scope of this study.

6.2. Average Crustal $V_{P} / V_{S}$

$V_{P} / V_{S}$ can be helpful to distinguish between felsic and mafic rocks as a matter of the relative proportions of quartz $\left(V_{P} / V_{S} \sim 1.49\right)$ and plagioclase $\left(V_{P} / V_{S} \sim 1.87\right)$ (Christensen, 1996). Crustal rocks can thereby be 


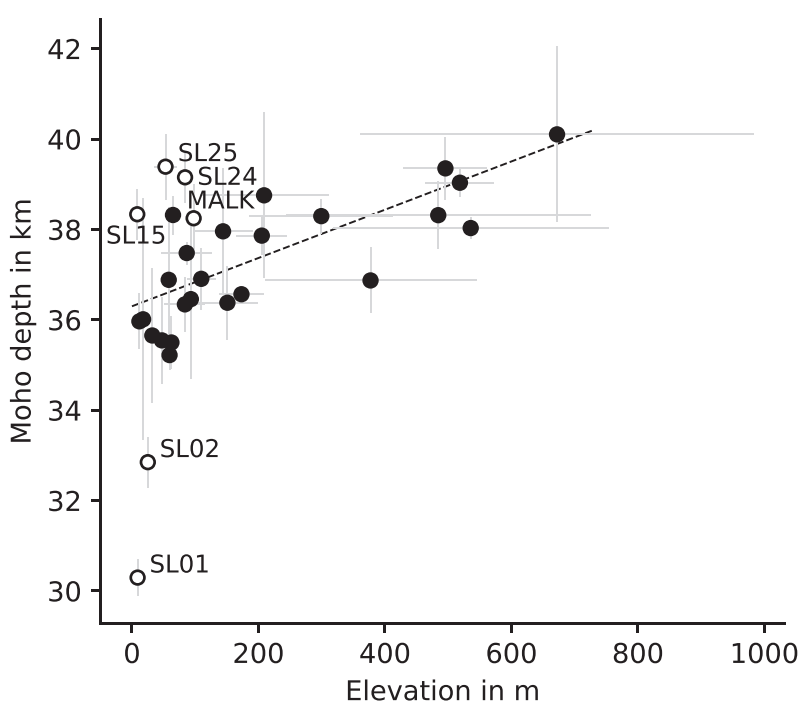

Figure 10. Relation between Moho depth from Bayesian inversion and elevation averaged over a $3 \mathrm{~km}$ radius. The majority of the stations (filled symbols) show a linear relation (dashed line) with a slope of 5.5. The hollow symbols show the outlying coastal stations SL01, SL02, and SL15, and the stations MALK, SL24, and SL25 that are located in the northern most part of the island. See text for explanation. subdivided into three categories (felsic, intermediate, and mafic) based on approximate $V_{P} / V_{S}$ boundaries at 1.75 and 1.80 . We classified the results from $\mathrm{H} \kappa$ stacking according to this subdivision (Figure 9, left). As only one of the $V_{P} / V_{S}$ ratios is larger than 1.80 , this would generally exclude a mafic composition. Our $V_{P} / V_{S}$ ratios are between 1.60 and 1.82 , indicating that most of Sri Lanka is represented by felsic to intermediate rocks with intermediate to high silica content (Christensen, 1996). As indicated in section 5 , the $V_{P} / V_{S}$ ratios derived from $\mathrm{H} \kappa$ stacking are more reliable than those derived from joint inversion. Also note that the $V_{P} / V_{S}$ estimates are crustal averages; it is possible that sections of the crust are dominated by different compositions. Sri Lanka shows average crustal $V_{S}$ between 3.7 and $3.9 \mathrm{~km} / \mathrm{s}$. Derived estimates for $V_{P}$ (Figure 9, left) are mostly between 6.3 and $6.7 \mathrm{~km} / \mathrm{s}$.

Most metamorphic rocks in Sri Lanka are of sedimentary and granitoid igneous heritage (see section 1.1) and suggest silica-rich protoliths. Although progressive metamorphism can be accompanied by systematic changes in plagioclase composition, which usually correlates to higher $V_{P} / V_{S}$ ratios (Christensen, 1996), the Sri Lankan crust is characterized by moderate $V_{P} / V_{S}$ ratios in spite of the high metamorphic grades of its geologic units. However, these values are not unusual for rocks with a similar geological history. Figure 9, right, compares $V_{P} / V_{S}$ ratios (and Moho depths) from Pan-African neighbors of Sri Lanka, which also experienced a high grade metamorphic overprint. The Precambrian domains of southern Madagascar (Rindraharisaona et al., 2017), the Kerala Khondalite Belt in southern India (Das et al., 2015; Rai et al., 2013), and single stations in Africa, Madagascar, southern India, Sri Lanka, and East Antarctica (Rai et al., 2009) show similarly low $V_{P} / V_{S}$ ratios between 1.65 and 1.78, thus also indicating felsic to intermediate bulk crustal compositions. The strong similarities of seismic crustal properties between the Pan-African terranes, and the lack of correlation of crustal $V_{P} / V_{S}$ and average $V_{S}$ to the surface geologic units in Sri Lanka, might be attributed to the region spanning unification of crustal structures through extensive overprinting during the Pan-African Orogeny. Differences might be seen as consequence of autochtone compositions and individual processes after the orogeny.

We observe a weak negative correlation between $V_{P} / V_{S}$ ratios and Moho depths derived in Sri Lanka (Figure 9, right, dashed line), which would indicate that a thicker crust is generally more felsic. However, to verify the correlation, more measurements would be necessary.

\subsection{Moho Depths and Intracrustal Features}

The Moho depths are not obviously correlated with the geologic units, which suggests that the crustal fragments have been unified through reworking and deformation through the Pan-African collision and possibly later erosive processes. The thinner crust along the west coast $(<36 \mathrm{~km})$, including the thinnest crust at SL01-SL03 (30-35 km), can be explained by the formation of the adjacent Mannar Basin, including rifting and crustal thinning. The Moho interface generally mirrors the topography (Figure 10), except for the thicker crust in the northernmost part of the island and the thinner crust along the west coast. These effects might be caused by density differences through crustal composition.

Our study reveals a major WNW dipping midcrustal interface in the central HC with an apparent dip of $\sim 4.3^{\circ}$ along the profile. Stations in the VC and close to the HC/VC border (i.e., SL12, SL19, SL23, and SL28) also show a discontinuity at a depth of $\sim 18 \mathrm{~km}$. It is unclear whether the four stations see the same structure as the stations in the HC or image a separate feature within the western VC. The midcrustal interface might be a feature from before the Pan-African collision; however, as the extent of the discontinuity from the HC into the western VC continues at the same depth and shows a coherent $V_{S}$ contrast, it is likely that the interface is the result of a shared event. Therefore, we are inclined to interpret this midcrustal feature as being related to the $\mathrm{HC} / \mathrm{VC}$ thrust contact.

A low-velocity layer as we observe at the central stations within the HC was also observed by Rai et al. (2009) in the upper crust of other Pan-African terranes. Low-velocity zones are thought to be caused by partial melts or the presence of fluids, which are able to depress the melting point and alter chemical rock compositions. 


\subsection{The Amalgamation of Sri Lanka}

Our $V_{S}$ models, Moho depths, and crustal average $V_{P} / V_{S}$ ratios provide information on the large-scale structure and bulk composition of the crust. An interpretation of these in terms of the complex amalgamation processes is therefore bound to be somewhat speculative. We consider it nevertheless worthwhile to discuss possible implications of our findings for the assembly of Sri Lanka. In the following, we try to interpret the origin of the midcrustal interface and the central low-velocity zone.

In the first scenario, we assume the midcrustal interface to be part of the HC before the collision. Based on eastward increasing pressures and temperatures across the granulite grade rocks, Newton and Hansen (1986) proposed the presence of a tilted crustal section. A metamorphic field gradient was supported by several later studies (Braun \& Kriegsman, 2003, see and references therein). Raase and Schenk (1994) found that the exposed lower crustal section of the HC was already tilted during cooling, that is, after peak metamorphic conditions and hence prior to thrusting over the VC. The dipping midcrustal interface in the HC might be an indicator for the proposed tilting: The crustal section experienced a tilt to the west, lifting deeper lying and higher metamorphic grade rocks in the east. The midcrustal interface in the western VC would then be a separate interface, showing similar depths and $V_{S}$ contrasts as observed in the eastern HC.

The second scenario is based on the interpretation of the midcrustal interface as westward dipping thrust contact between the HC and the VC. Kleinschrodt $(1994,1996)$ suggested that the HC was thrust onto the VC along a deep crustal, subhorizontal to gently west dipping thrust surface, which underlies large parts of the HC. A proposed geometry is a low-angle thrust that steepens to shallower crustal levels (Figure 8a). The midcrustal interface we observe matches the proposed position and orientation of the HC/VC thrust contact. However, the implied connection of this structure to the shallow contact between the units is beyond the resolution capability of our data. A relation between the midcrustal converter to the $\mathrm{HC} / \mathrm{VC}$ thrust contact is supported by the continuation of the interface from the $\mathrm{HC}$ into the $\mathrm{VC}$ at the same depth with similar values of $V_{S}$ underneath. As the underlying footwall (VC) seems to show only high $V_{S}$ lower crust underthrusting the $\mathrm{HC}$, this could support the interpretation of the $\mathrm{VC}$ or unexposed crustal domains underlying the VC to be a colliding promontory (Braun \& Kriegsman, 2003). Brun and Burg (1982) proposed such a model for the Ibero-Armorican arc and showed that an indenting promontory in a continental collision leads to a "corner-effect," inducing thrusting and wrenching at the same time. The footwall thereby shows typically only minor syntaxial bending, while the upper plate can show a strongly curved arc. The highly complicated structures found along the $\mathrm{HC} / \mathrm{VC}$ thrust contact could possibly be explained by such a model (Kriegsman, 1995). The high $V_{S}$ interlayered with lower $V_{S}$ observable below the midcrustal interface at stations SL11-SL13 (Figure 7) could therefore reflect the complicated deep contact zone between the HC and the VC.

The low-velocity layer in the $\mathrm{HC}$ along the main profile ( $\sim 10 \mathrm{~km}$ depth) might be caused by influx of $\mathrm{CO}_{2}$-rich fluids. Fluid inclusions in granulite facies rocks show high proportions of $\mathrm{CO}_{2}$, whereas fluid inclusions in amphibolite facies rocks are usually rich in $\mathrm{H}_{2} \mathrm{O}$ (Hanson, 1980). The $\mathrm{CO}_{2}$-rich fluids could have been released by retrograde metamorphism to amphibolite facies, which occurred in the $\mathrm{HC}$ during the thrusting of the HC on top of the VC (Kleinschrodt, 1994). Fossil reservoirs or traps of carbonic fluid inclusions in the deeper crustal granulites were discussed for southern India in the context of charnockite formation. Raith et al. (1989) argued that charnockitization was triggered by massive influx of carbonic fluids, which were released by shear deformation. Charnockitization also occurred in central to western Sri Lanka (e.g., Santosh, 1991), suggesting a similar scenario. We note that the described scenario of $\mathrm{CO}_{2}$-rich fluid release involves $\mathrm{HC} / \mathrm{VC}$ thrusting; the upper crustal low-velocity zone coincides with the central thrusting contact zone, suggesting a correlation.

\section{Conclusions}

Rayleigh wave dispersion curves from ambient noise correlation and RFs were computed and jointly inverted using McMC transdimensional Bayesian inversion. Based on the median of the posterior distributions obtained from each station, we evaluated the crustal velocity structure of Sri Lanka.

Our results show a Moho interface at 30-40 km depth with a distinct velocity increase. The lower Moho depths along the west coast emerged presumably through rifting and crustal thinning processes through the formation of the adjacent Mannar Basin. The Moho depths show no correlation to the geologic units and largely mirror the topography, which suggests Airy isostacy for most of the Sri Lankan continental crust. 
A thicker crust in the northernmost part of the island and the thinner crust along the west coast might be caused by compositional effects on density.

We identified a prominent midcrustal interface beneath the $\mathrm{HC}(18-27 \mathrm{~km})$ and the western $\mathrm{VC}(\sim 18 \mathrm{~km})$. This westward dipping interface in the $\mathrm{HC}$ and the interface within the VC might have been part of the respective units before the thrusting event in the Pan-African collision and could be an indicator for the proposed tilting of the $\mathrm{HC} / \mathrm{WC}$ crustal sections. Alternatively, it might be related to the deep crustal $\mathrm{HC} / \mathrm{VC}$ thrust contact; this interpretation implies that the $\mathrm{VC}$ acts as an indenting promontory of high $V_{S}$. A low-velocity zone in the central HC might be caused by metasomatism through fluid influx related to thrusting during the collision.

\section{Acknowledgments}

Many thanks to Robert Trumbull for the vivid discussions about geologic interrelationships. We thank the GSMB of Sri Lanka, who made it possible to deploy a temporary seismic network in Sri Lanka, and their employees for their support and engagement during the field work. We acknowledge the GFZ for funding the field experiment from expedition funds, the Geophysical Instrument Pool Potsdam (GIPP) for supplying the instruments, the GEOFON data center for hosting the project data (https:// geofon.gfz-potsdam.de/waveform/ archive), and research support through Grant TI316/4-1 awarded by the Deutsche Forschungsgemeinschaft DFG. We thank Walter Mooney and an anonymous reviewer for constructive review comments, which helped to improve this paper. The data of the final crustal model of Sri Lanka are published as Dreiling et al. (2020) and downloadable at the GFZ Data Services (https://doi.org/10.5880/ GFZ.2.4.2020.001).

\section{References}

Aki, K. (1957). Space and time spectra of stationary stochastic waves, with special reference to microtremors. Bulletin of the Earthquake Research Institute, University of Tokyo, 35, 415-456.

Bensen, G. D., Ritzwoller, M. H., Barmin, M. P., Levshin, A. L., Lin, F., Moschetti, M. P., et al. (2007). Processing seismic ambient noise data to obtain reliable broad-band surface wave dispersion measurements. Geophysical Journal International, 169(3), 1239-1260. https://doi. org/10.1111/j.1365-246X.2007.03374.x

Bodin, T., Sambridge, M., Tkalčić, H., Arroucau, P., Gallagher, K., \& Rawlinson, N. (2012). Transdimensional inversion of receiver functions and surface wave dispersion. Journal of Geophysical Research, 117, B02301. https://doi.org/10.1029/2011JB008560

Braun, I., \& Kriegsman, L. M. (2003). Proterozoic crustal evolution of southernmost India and Sri Lanka. Geological Society, London, Special Publications, 206(1), 169-202. https://doi.org/10.1144/GSL.SP.2003.206.01.10

Brun, J.-P., \& Burg, J.-P. (1982). Combined thrusting and wrenching in the Ibero-Armorican arc: A corner effect during continental collision. Earth and Planetary Science Letters, 319-332.

Christensen, N. I. (1996). Poisson's ratio and crustal seismology. Journal of Geophysical Research, 101(B2), 3139-3156. https://doi.org/10. 1029/95JB03446

Cooray, P. G. (1994). The precambrian of Sri Lanka: A historical review. Precambrian Research, 66(1), 3-18. https://doi.org/10.1016/ 0301-9268(94)90041-8

Das, R., Saikia, U., \& Rai, S. S. (2015). The deep geology of South India inferred from Moho depth and Vp/Vs ratio. Geophysical Journal International, 203(2), 910-926. https://doi.org/10.1093/gji/ggv351

Dissanayake, C. B., \& Chandrajith, R. (1999). Sri LankaMadagascar Gondwana linkage: Evidence for a PanAfrican mineral belt. The Journal of Geology, 107(2), 223-235. https://doi.org/10.1086/314342

Dreiling, J., \& Tilmann, F. (2019). BayHunter-McMC transdimensional Bayesian inversion of receiver functions and surface wave dispersion Potsdam, Germany: GFZ Data Services. https://doi.org/10.5880/GFZ.2.4.2019.001

Dreiling, J., Tilmann, F., Yuan, X., Haberland, C., \& Seneviratne, S. W. M. (2020). Seismic crustal model of Sri Lanka. Potsdam, Germany: GFZ Data Services. https://doi.org/10.5880/GFZ.2.4.2020.001

Ekström, G., Abers, G. A., \& Webb, S. C. (2009). Determination of surface-wave phase velocities across USArray from noise and Aki's spectral formulation. Geophysical Research Letters, 36, L18301. https://doi.org/10.1029/2009GL039131)

GEOFON Data Centre (1993). GEOFON seismic network. Deutsches GeoForschungsZentrum GFZ. https://doi.org/10.14470/TR560404

Hanson, G. N. (1980). Geochemical evolution of the continental crust in Continental Tectonics. In The National Academy of Sciences, Studies in geophysics (pp. 151-158). Washington DC: National Academy Press.

Huang, Y., Chubakov, V., Mantovani, F., Rudnick, R. L., \& McDonough, W. F. (2013). A reference Earth model for the heat-producing elements and associated geoneutrino flux. Geochemistry, Geophysics, Geosystems, 14, 2003-2029. https://doi.org/10.1002/ggge.20129

Kehelpannala, K. V. W. (1997). Deformation of a high-grade Gondwana fragment, Sri Lanka. Gondwana Research, 1(1), 47-68. https://doi. org/10.1016/S1342-937X(05)70005-8

Kehelpannala, K. V. W. (2003). Structural evolution of the middle to lower crust in Sri Lanka-A review. Journal of the Geological Society of Sri Lanka, 11, 45-85.

Kehelpannala, K. V. W. (2004). Arc accretion around Sri Lanka during the assembly of Gondwana. Gondwana Research, $7(4), 7$.

Kind, R., Yuan, X., \& Kumar, P. (2012). Seismic receiver functions and the lithosphere-asthenosphere boundary. Tectonophysics, 25-43.

Kleinschrodt, R. (1994). Large-scale thrusting in the lower crustal basement of Sri Lanka. Precambrian Research, 66(1-4), 39-57.

Kleinschrodt, R. (1996). Strain localization and large-scale block rotation in the lower continental crust, Kataragama area, Sri Lanka. Terra Nova, 8(3), 236-244. https://doi.org/10.1111/j.1365-3121.1996.tb00752.x

Kriegsman, L. M. (1994). Evidence for a fold nappe in the high-grade basement of central Sri Lanka: Terrane assembly in the Pan-African lower crust? Precambrian Research, 66(1-4), 59-76. https://doi.org/10.1016/0301-9268(94)90044-2

Kriegsman, L. M. (1995). The Pan-African event in East Antarctica: A view from Sri Lanka and the Mozambique Belt. Precambrian Research, 75(3), 263-277. https://doi.org/10.1016/0301-9268(95)80010-F

Kröner, A., \& Brown, L. (2005). Structure, composition and evolution of the south Indian and Sri Lankan granulite terrains from deep seismic profiling and other geophysical and geological investigations: A LEGENDS initiative. Gondwana Research, 8(3), 317-335. https:// doi.org/10.1016/S1342-937X(05)71138-2

Kröner, A., Cooray, P. G., \& Vitanage, P. W. (1991). Lithotectonic subdivision of the Precambrian basement in Sri Lanka. In A. Kröner (Ed.), The crystalline crust of Sri Lanka, Part I, Summary of research of the German-Sri Lanka consortium. Geological Survey Department of Sri Lanka, Professional Paper (Vol. 5, pp. 5-21). Lefkosia.

Kröner, A., Jaeckel, P., \& Williams, I. S. (1994). Pb-loss patterns in zircons from a high-grade metamorphic terrain as revealed by different dating methods: U-b and $\mathrm{Pb}-\mathrm{Pb}$ ages for igneous and metamorphic zircons from northern Sri Lanka. In M. Raith, \& S. Hoernes (Eds.), Tectonic, metamorphic and isotopic evolution of deep crustal rocks, with special emphasis on Sri Lanka. Precambrian Research (Vol. 66, pp. 151-181). https://doi.org/10.1016/0301-9268(94)90049-3

Kularathna, E. K. C. W., Pitawala, H. M. T. G. A., Senaratne, A., Senevirathne, B. S. M. C. K., \& Weerasinghe, D. A. (2015). Forced-fold structures in the Mannar Basin, Sri Lanka: Modes of occurrence, development mechanism and contribution for the petroleum system. Journal of Geological Society of Sri Lanka, 17, 12.

Mahalanobis, P. C. (1936). On the generalized distance in statistics. 
Mishra, D. C., Kumar, V. V., \& Rajasekhar, R. P. (2006). Analysis of airborne magnetic and gravity anomalies of peninsular shield, India integrated with seismic and magnetotelluric results and gravity anomalies of Madagascar, Sri Lanka and East Antarctica. Gondwana Research, 10(1-2), 6-17. https://doi.org/10.1016/j.gr.2005.11.014

Mukherjee, P., Borah, K., \& Bora, D. K. (2020). Nature of crust beneath Sri Lanka using teleseismic receiver function. Journal of Asian Earth Sciences, 187. https://doi.org/10.1016/j.jseaes.2019.104096

Newton, R. C., \& Hansen, E. C. (1986). The South India-Sri Lanka high-grade terrain as a possible deep-crust section. Geological Society, London, Special Publications, 24, 297-307. https://doi.org/10.1144/GSL.SP.1986.024.01.26

Pathak, A., Kumar, M. R., \& Sarkar, D. (2006). Seismic structure of Sri Lanka using receiver function analysis: A comparison with other high-grade Gondwana terrains. Gondwana Research, 10(1), 198-202. https://doi.org/10.1016/j.gr.2005.10.006

Prasanna, H. M. I., Chen, W., \& Iz, H. B. (2013). High resolution local Moho determination using gravity inversion: A case study in Sri Lanka. Journal of Asian Earth Sciences, 74, 62-70. https://doi.org/10.1016/j.jseaes.2013.06.005

Raase, P., \& Schenk, V. (1994). Petrology of granulite-facies metapelites of the Highland Complex, Sri Lanka: Implications for the metamorphic zonation and the P-T path. Precambrian Research, 66(1-4), 265-294. https://doi.org/10.1016/0301-9268(94)90054-X

Rai, S. S., Borah, K., Das, R., Gupta, S., Srivastava, S., Prakasam, K. S., et al. (2013). The South India Precambrian crust and shallow lithospheric mantle: Initial results from the India Deep Earth Imaging Experiment (INDEX). Journal of Earth System Science, 122(6), 1435-1453. https://doi.org/10.1007/s12040-013-0357-0

Rai, A., Gaur, V. K., Rai, S. S., \& Priestley, K. (2009). Seismic signatures of the Pan-African orogeny: Implications for southern Indian high-grade terranes. Geophysical Journal International, 176(2), 518-528. https://doi.org/10.1111/j.1365-246X.2008.03965.x

Raith, M., Hoernes, S., Klatt, E., \& Stähle, H. J. (1989). ontrasting Mechanisms of Charnockite Formation in the Amphibolite to Granulite Grade Transition Zones of Southern India. In D. Bridgwater (Ed.), Fluid Movements - Element Transport and the Composition of the Deep Crust, NATO ASI Series (Series C: Mathematical and Physical Sciences) (Vol. 281, pp. 29-38). Dordrecht: Springer. https://doi.org/ 10.1007/978-94-009-0991-5_3

Rawlinson, N. (2005). FMST: Fast marching surface tomography package-Instructions. Research School of Earth Sciences, Australian National University, Canberra ACT 0200.

Rawlinson, N., \& Sambridge, M. (2005). The fast marching method: An effective tool for tomographic imaging and tracking multiple phases in complex layered media. Exploration Geophysics, 36(4), 341. https://doi.org/10.1071/EG05341

Rindraharisaona, E. J., Tilmann, F., Yuan, X., Rümpker, G., Giese, J., Rambolamanana, G., \& Barruol, G. (2017). Crustal structure of southern Madagascar from receiver functions and ambient noise correlation: Implications for crustal evolution. Journal of Geophysical Research: Solid Earth, 122, 1179-1197. https://doi.org/10.1002/2016JB013565

Royer, J.-Y., \& Coffin, M. F. (1992). Jurassic to Eocene plate tectonic reconstructions in the Kerguelen Plateau region. In S. W., J. Wise, A. P. Julson, R. Schlich, \& E. Thomas (Eds.), Proceedings of the Ocean Drilling Program, Scientific Results, vol. 120. Ocean Drilling Program, Texas A-M University, College Station, TX, pp. 917-930.

SIO (1996). Global Seismograph Network - IRIS/IDA. International Federation of Digital Seismograph Networks. Dataset/Seismic Network. Scripps Institution of Oceanography (SIO), San Diego. https://doi.org/10.7914/SN/II

Sadeghisorkhani, H., Gudmundsson, O., \& Tryggvason, A. (2017). GSpecDisp: A Matlab GUI package for phase-velocity dispersion measurements from ambient-noise correlations. Computers \& Geosciences, 110, 41-53. https://doi.org/10.1016/j.cageo.2017.09.006

Sandiford, M., Powell, R., Martin, S. F., \& Perera, L. R. K. (1988). Thermal and baric evolution of garnet granulites from Sri Lanka. Journal of Metamorphic Geology, 6(3), 351-364. https://doi.org/10.1111/j.1525-1314.1988.tb00425.x

Santosh, M. (1991). Role of CO2 in granulite petrogenesis evidence from fluid inclusions. Journal of Geosciences, Osaka City University, 34, $1-53$.

Seneviratne, S. W. M., Haberland, C., \& Dreiling, J. (2016). Sri Lanka temporary broadband network. https://doi.org/10.14470/ 6 N7561723039

Zhu, L., \& Kanamori, H. (2000). Moho depth variation in southern California from teleseismic receiver functions. Journal of Geophysical Research, 105, 2969-2980. 